\title{
BEYOND GRAPHICS: INFORMATION An overview of infovis practices in the field of the architectural heritage
}

\author{
J.Y Blaise, I.Dudek \\ UMR CNRS/MCC 694 MAP, 184 av de Luminy, 13288 Marseille Cedex 09, France \\ jyb@map.archi.fr,idu@map.archi.fr
}

Keywords: Architectural heritage, Information visualisation, Graphic representation.

\begin{abstract}
Understanding and representing the evolution of architectural artefacts over time requires a careful examination of heterogeneous, questionable pieces of data. Accordingly, our position is that computer graphics can and will support such investigation if and only if they are designed, above all, as information visualisation disposals (may the visual result be realistic or not). But contemporary practices often fail to reach this goal. In this paper, we propose possible explanations, and argue why we believe the problem has more to do with a lack of appropriate methodology than with technologies. As an answer, we introduce a global methodological framework that claims to be at the intersection of figurative architectural representation and of information visualisation. We finally back up this claim by presenting past and contemporary examples showing there has been a bridge between the above mentioned fields, a bridge that we today need to rebuild with or against computer technologies.
\end{abstract}

\section{INTRODUCTION}

Computer graphics, and VR in particular, have had in the past decade a growing influence on how results of investigations about heritage architecture can be presented. Their use has constantly widened, with applications ranging for instance from the exploitation of archaeological studies (Ando, 2003), to survey processes engineering (De Luca, 2005); and with various scales observed (ranging from cities (Lerma, 2004) to architectural interiors (Perkins, 2003). However in numerous research works architecture has served mainly as a test bench. A good example can be found in (Suveg, 2004) where urban architecture, illustrating a research on geometric reconstruction, is described only through three parametric building models called primitives: flat roof , symmetrical gable roof building, nonsymmetrical gable roof building (sic...).

When looking at architectural-heritage centered expriments, one can observe that $3 \mathrm{D}$ models have been widely used to portray "how a site could have looked like in the past". Their application to virtual reconstruction (a questionable wording since reconstruction implies more than bare re-drawing), clearly has had an impact in terms of communication. However, at this stage they remain criticised and raise a number of questions among researchers and practitioners (see Kantner, 2000). Two points can be mentioned:

- a lack of readability of the representations (inferences made for the reconstruction of the objects are obscured in the final image);

- a lack of efficiency: researchers put time and means into producing realistic 3D models which remain an edge effect of their study. Such model is not linked to the sources justifying the content, it is not dynamically up-dated when new information is collected, and it does not mention what is in the most important for the analyst - the uncertainty of the initial data.

And indeed, recent experiments with realistic 3D modelling of heritage architecture like the "Krakow 1650 3D model" (MHK, 2007) show there is a growing concern, even in the context of scientific popularisation, for less assertive visual results.

Considering the variety and powerfulness of tools available, and the number of experiments carried out, we believe it is time to sit and analyse where and why, when applied to heritage architecture, computer graphics often fail to be effective investigation tools for scientists. In this paper's first section we propose two possible explanations.

We also intend to show that, with the growing influence of computers on their activity, researchers in the field of the architectural heritage now need to 
innovate in terms of method. Our position is that computer graphics will help thinking only if researchers and practitioners design them as J.Bertin calls "work and discovery tools (Bertin, 1998). So the question is why are graphics in the field of the architectural heritage so far from it, why are they so often hopelessly meaningless, even when they "look good". And our claim is that it's a matter of methodology. Consequently, in this paper's second section we introduce a possible methodological framework called "informative modelling" that integrates legacies from the fields of architectural modelling and of information visualisation.
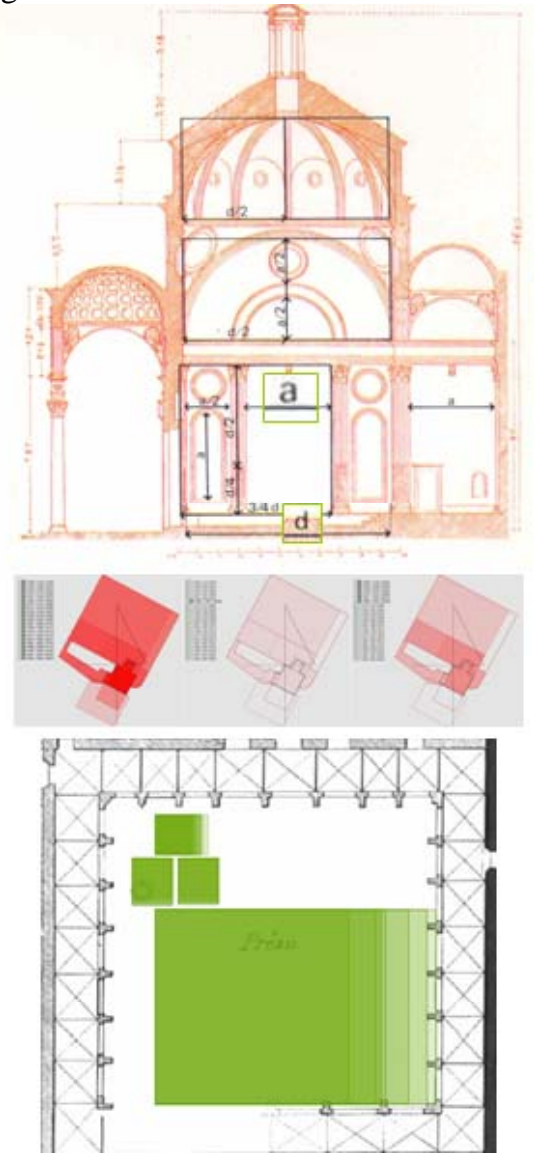

Figure 1: Three information envisioning practices quoted in (Tufte, 1997), here illustrated in the field of architectural representation. Top, place the data in an appropriate context for assessing cause and effect: the data (here dimensions of this chapel by Brunelleschi), is compared to exterior metrics (ratios a and d) in order to better understand the object's composition, (Fanelli, 1980). Middle, make quantitative comparisons : in this SVG graphic (Dudek, 2005) a comparison of layouts in plan, with cumulative colouring (each evolution, or chronological layer, can interactively be switched on /off). Bottom, consider alternative explanations and contrary cases : in this trivial visual display the variability of vaults dimensions across the background cloister is uncovered.
But to which extent are these a-priori distinct fields compatible? (Figure 1) Our second claim will be that those two fields can fruitfully complement one another when dealing with what is at the heart of historic artefacts : partial evidences. So in this paper's third section we will try to demonstrate through historic as well as contemporary graphic designs that it is so.

\section{APPLICATION FIELD SPECIFIC BOTTLENECKS}

So are solutions from the field of computer graphics (partly) ill-suited to the field of the architectural heritage? In this section we discuss two arguments that we believe help delineating more accurately the actual difficulties, but also that tend to show the blame may need to be shared between technologies and what we do with them.

\section{1 partial data vs exhaustive geometry}

Studying how an edifice or a site has changed over time is primarily an information uncovering and analysis task. Researchers carrying out this task are faced with partial, heterogeneous, often questionable evidence. An in-depth analysis of the various pieces of evidence one can gather may help understanding scraps of its history, with ever less density as we go backwards in time.

In other words, when the time has come to recount visually the evolution of a site, numerous shortages remain in the information set. It may be established for instance that an object existed between T1 and $\mathrm{T} 2$, but without enough indications on where it was, and how it looked like. Alternatively, it may be established by analysing archival sources that an object existed in position $\mathrm{P}$, but without indications on when it was erected, or on how it looked like.

In parallel, a 2D/3D modelling solution will require an exhaustive description of the site. A given $\mathrm{x}, \mathrm{y}(\mathrm{z})$ is needed for each point, a given shape needs to be drawn, etc.

And so ultimately, researchers are faced with an incontrovertible fact: they are most often asked to draw more than they really know. This observation is corroborated in (Lecuyot, 2005): the archaeologist commenting a virtual reconstruction produced for television says "..images are more demanding than text of publications since they do not allow for architectural omissions..". With a bit of subjectivity, 
one could read "even when we don't know we have to draw". Of course the popularisation of research result may be a valuable objective. But (Alkhoven, 2006) underlines the danger of graphics-that-don'tsay-that-they-cheat when she writes "documentation of choices for $3 D$ modelling is a pre requisite for scientific research because these images will lead their own life and others will base their research upon these images" (Figure 2).

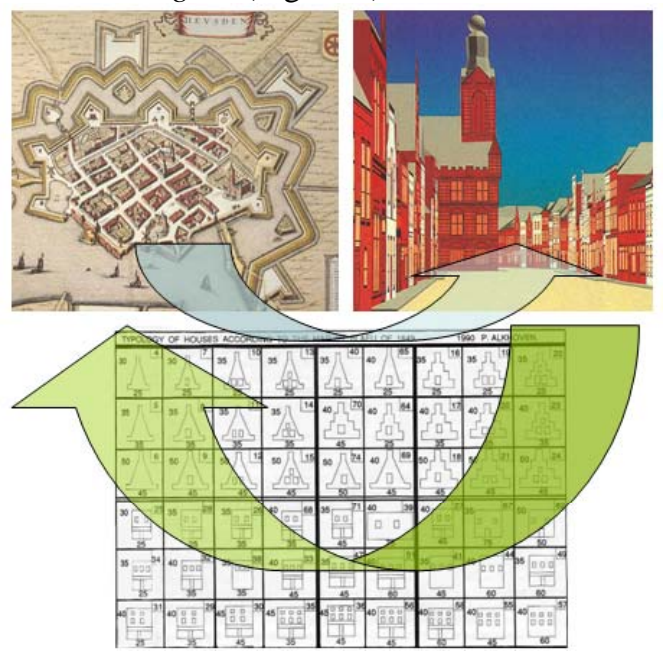

Figure 2: To and fro the sources: P.Alkhoven's analysis of Heusden's urban fabric as a documentation of choices

So how can we bridge the gap between incomplete, imprecise data sets and exhaustive 3D modelling? Documenting choices is here vital, as mentioned by P. Alkhoven, and beyond this both visualising these choices and giving access to these choices on the long run (Alkhoven, 1993, Dudek, 2007). 3
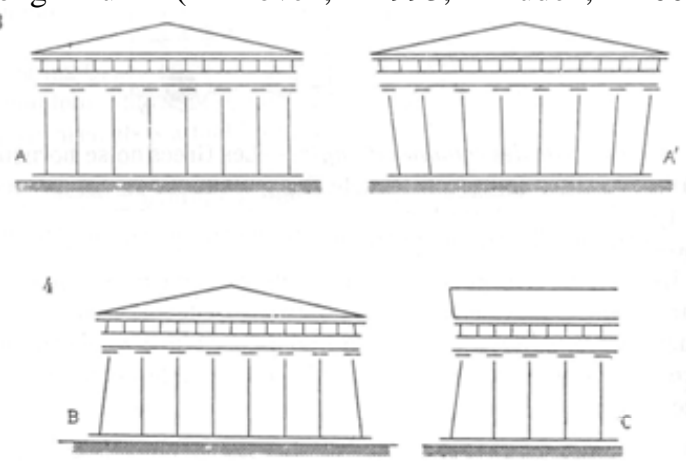

Figure 3: Choisy's drawings do not correspond to the real geometry of Greek compositions, but provide a real information to the reader: top, right, the illusion of divergence that the human eye naturally perceives, bottom, the corrective disposal adopted by ancient Greeks.

In his analysis of Minard's contribution to statistical graphics (C.J Minard, XIXth century pioneer of thematic cartography), M.Friendly (Friendly, 1999) gives us yet another hint when he writes "Minard almost invariably chose accuracy of data over the tyranny of precise geographical position when conflict arose". And this is in a way what the XIXth century architect Choisy (Choisy, 1899) does in his explanation of how ancient Greeks handled visual effects in the composition of porticos (Figure 3).

And so the point is that whatever tools we are given, may they be those of the XIXth century or those of the XXIst century, it is our responsibility as users of those tools to invent methods that will allow us not to draw what we don't know in a way that could let others think that we know, but to draw all of what we know in an information-enhancing way.

\subsection{Representation vs. visualisation}

When facing the necessity to provide visual results of an investigation, researchers or practitioners in our application field will most often end up using a 3D modelling software. Our position is that prior to using this or that tool, superseding other issues, is this question: representation or visualisation?

In the tradition of architectural drawing, representations are most often more or less figurative (including when foreseeing future architecture, as demonstrated in Estevez, 2001). On the contrary, visualisation is for (Spence, 2001) a cognitive activity, wherein the objective is a gain of insight, and the result a mental image.

But looking at it from closer, this may not be an opposition. When E.R Tufte (Tufte, 1990) writes "we envision information to reason about knowledge, to document, to communicate and preserve this knowledge" he undoubtedly covers the activity of researchers involved in our field. And so the first question is not how we envision but why. Furthermore, J.Bertin defines graphic representation as a "system of signs that humans have developed to retain, understand and communicate the observations that they need" (Bertin, 1998). Thereby the key is given: finding a system of signs that would be suited to our observations. And our observations are incomplete, imprecise etc, ... In addition, our observations are time-related. In short, one could say that the visualisation of artefacts changes is to architectural representation what time geography (Lenntorp, 2003) is to cartography.

To sum it up, our position is that we should keep in mind the ultimate goal: visualising information. And once again, whatever tools we are given, it appears that better practices can solve the opposition observed between figuration and abstraction. 


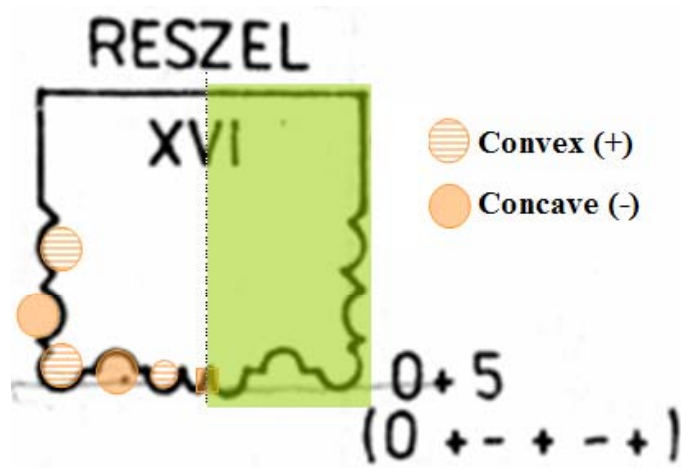

Figure 2: A brilliant integration of figurative drawing with abstract visualisation from (Tajchman 1989) : a specific ceiling beam observed in the town of Reszel (Poland) is described as alternate convex/concave mouldings (on its half-section). Zero identifies a flat zone on its axis. The beam is a " $\mathrm{O}+5$ ", an easier formalism for data treatment.

\section{A METHODOLOGICAL FRAMEWORK}

In the previous section we hope to have demonstrated that, when visualising information about artefact changes, tools do not forbid nor encourage good practices (although computer tools do have a strong influence, the nature of which we wish not to detail inside this contribution): So if the blame cannot be put on the tools, then maybe on lacking methods? As an answer, we have introduced in (Dudek, 2005) methodological framework called informative modelling.

We perceive informative modelling as a bridge between information visualisation and architectural modelling. From the latter it inherits a priority given to $2 \mathrm{D} / 3 \mathrm{D}$ space-enabled disposals. From the former it inherits an ambition to amplify cognition (Kienreich, 2006) about the artefact. Informative modelling applies to the study of historic architecture, where objects have most often been widely transformed, and consequently where what is known about objects remains partial. As a consequence, whereas in traditional architectural modelling a realistic representation of objects is considered as an end, in the informative modelling methodology the representation of architectural objects is used primarily as support for information search and visualisation, and does not strive for realism. Abstraction (the infovis legacy) and figuration (the architectural representation legacy) are integrated as alternative/mixable modes of representation, allowing partial knowledge to be communicated and important notions in historic sciences such as data uncertainty to be conveyed graphically. In (Dudek, 2007) we have introduced a grid of fourteen modelling rules (plus one), designed as safeguards helping researchers to support their activity with sustainable and information-effective graphics. These rules are nothing more than a best-practice grid, but encompassing a wide range of issues: they are actually divided into four groups (information, models, representations, abstractions). The fifteenth rule will give the reader an idea of what informative modelling is all about: If a 2D/3D model does not produce a gain of insight into the underlying information - it should be considered worthless.

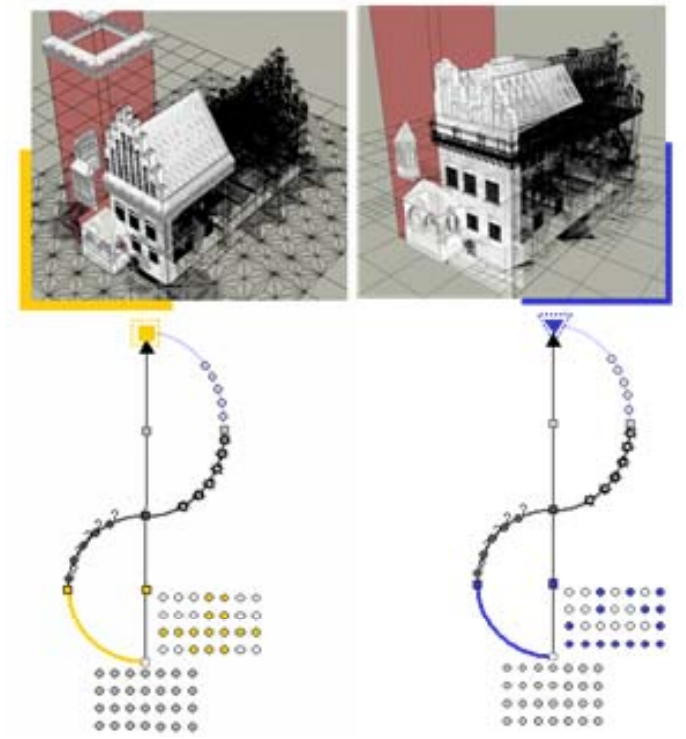

Figure 2: An illustration of rule $n^{\circ} 2$ (Dudek, 2007): "The representation of an object will allow the user to retrieve data and information that justify the presence of the object at the time and date the representation shows." From various information sub-sets various layouts can be derived: a representation shoud allow the user to be aware of the choices made by the author of the reconstruction. Shown here two layouts corresponding to two selections inside the information set on Kraków's old town hall. (from the left to right : reconstructions by F. Christ (1950) and A. Essenwein (1869))

In short, we made a claim: there is a bridge between architectural modelling, and information visualisation. This claim has been repeatedly examined through practical applications. In this contribution we wish to further support this claim by presenting a bunch of examples showing where architectural representation and information visualisation have met in past practices, and can still meet with (or against) computer solutions. E.R Tufte's layering and separation (Tufte, 1990) in graphic design gives us here a good thematic frame. 


\section{VISUAL STRATIFICATION}

Studying the evolution of architectural and urban artefacts requires taking into consideration numerous information sets. But due to the complexity and heterogeneity of this information, visualising the evidences about artefacts - through 2D/3D models can end up in confusion and disorder. Interfacing the information sets exploited during the analysis of an artefact hereby raises a new methodological issue: operating selections and stratification in order to lighten the cognitive effort. In the field of information visualisation, E.R. Tufte (Tufte, 1990) acknowledges the importance of this information stratification step (prior to the making of a representation) in those words : "[...] among the most powerful devices for reducing noise and enriching the content of displays is the technique of layering and separation [...]". Today's tools (GIS, CAD tools, etc.) do provide technical possibilities for layering and separating information, but give no hints on how to perform the selection itself with regards to the specificity of the information and/or of the geometric objects in charge of localising the information. In the tables below, we propose examples of application of the above mentioned principles in architectural representation.

Table 1: Disciplinary stratification:

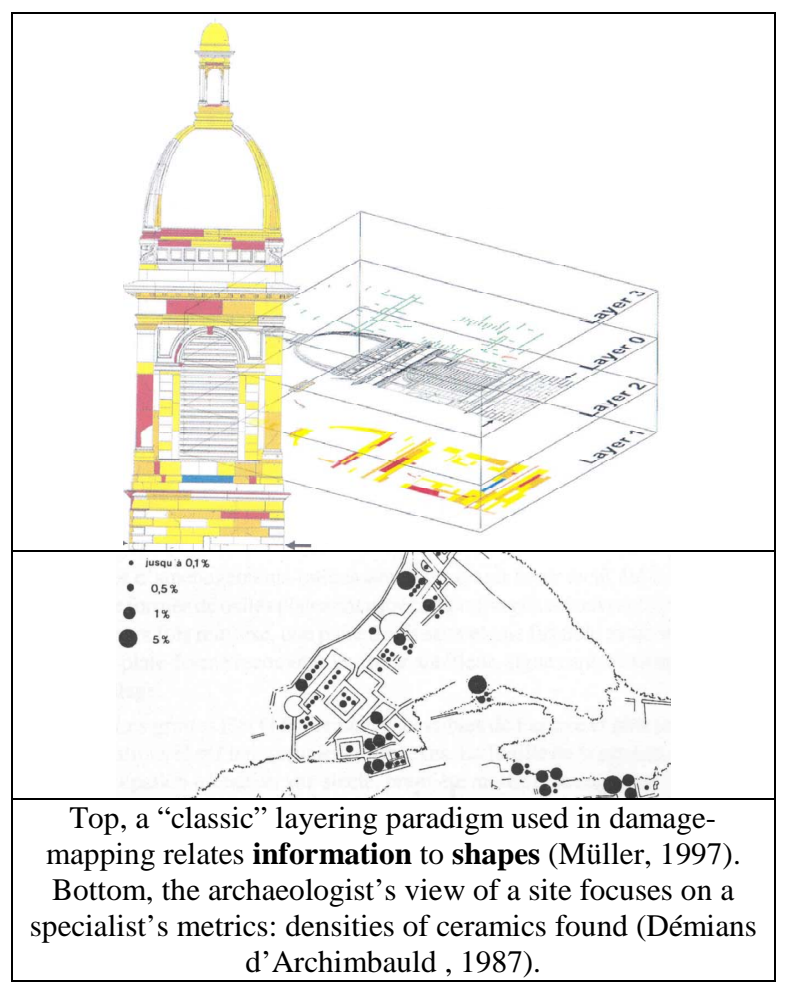

Table 2: Temporal stratification.
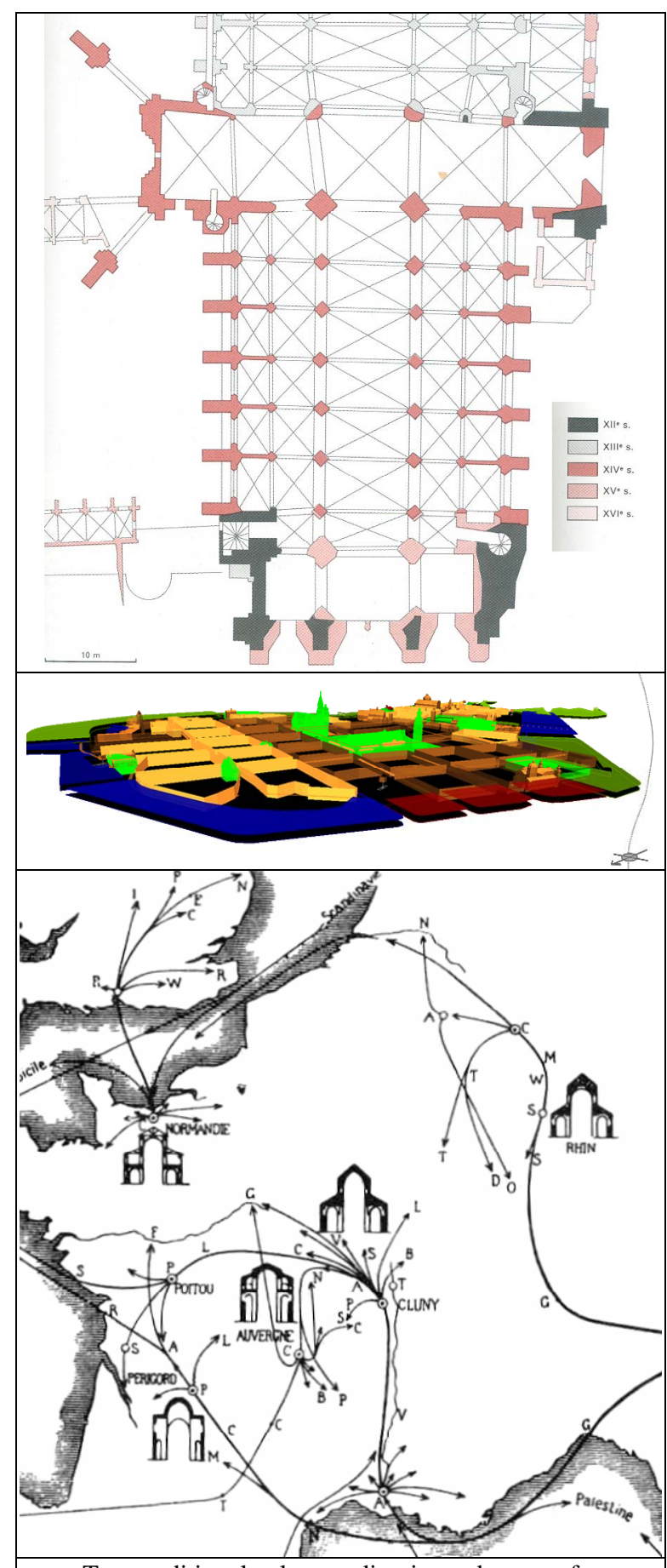

Top, traditional colour-coding is used to transfer information about periods of construction within an edifice (Pérouse, 1995). Middle, colour coding is extended to certainty and justification assessments in this VRML interface (Dudek, 2005). Bottom, in this masterly visualisation, A. Choisy recounts the spatio-temporal development of the main Romanesque schools with a combination of cartography and sections (Choisy, 1899). 
Table 3: Spatial stratification

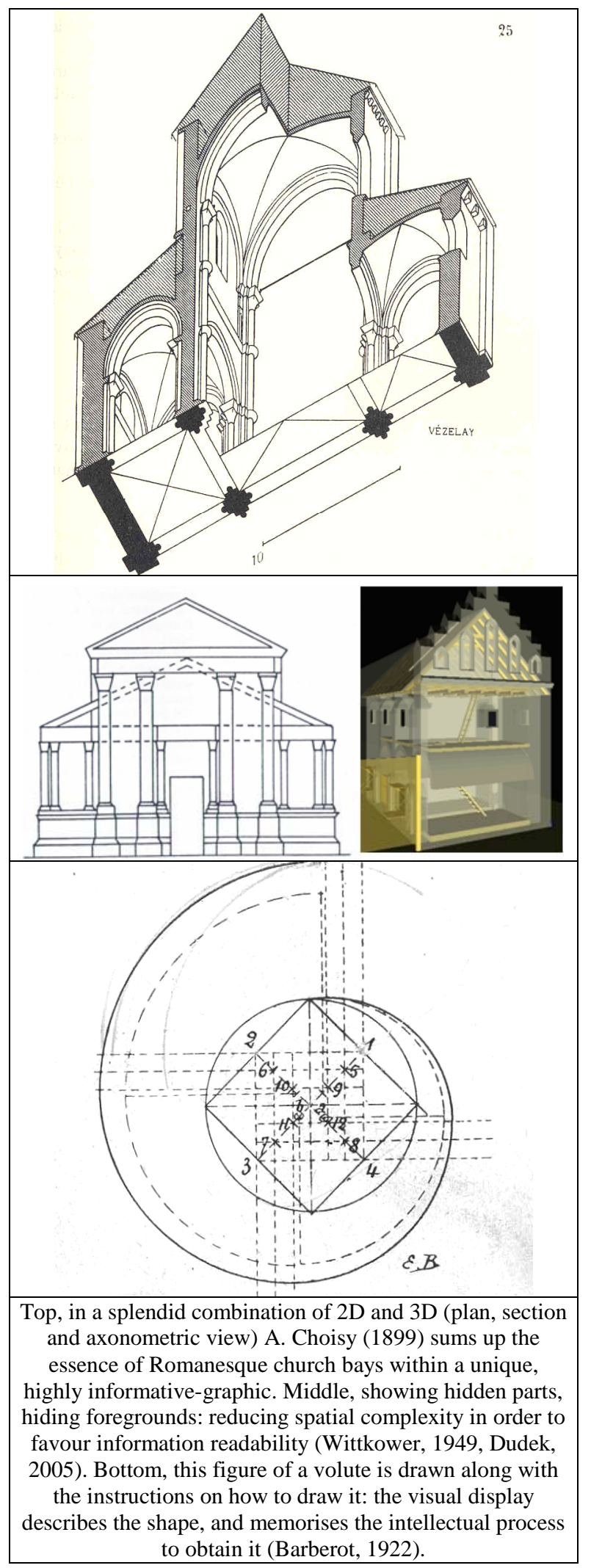

Table 4: Informative stratification.

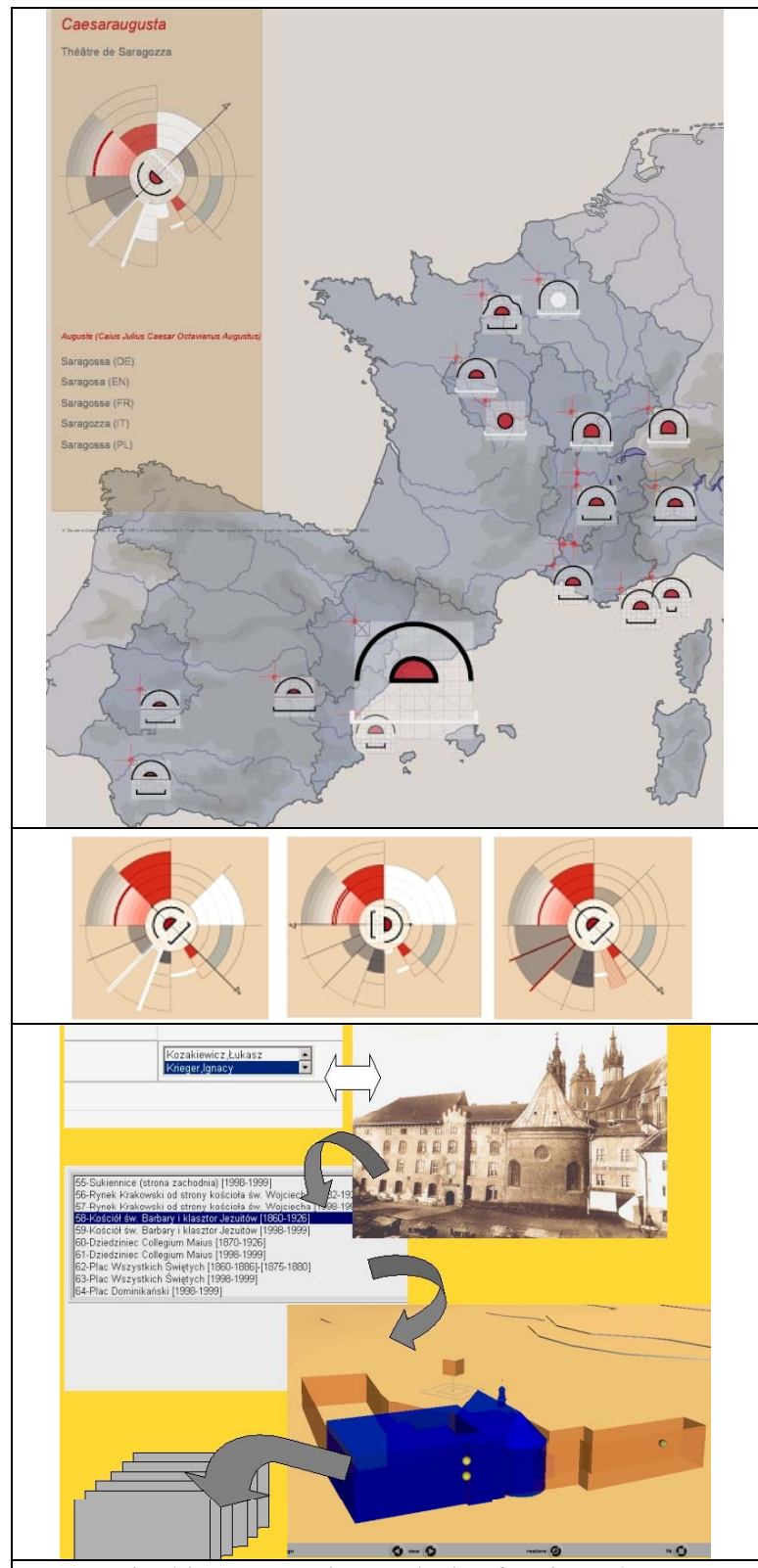

Top, in this comparative analysis of antique theatres (Blaise, 2006), a graphic symbol delivers a first level of information on the location and typology. Selection of a location opens (top left of the image) a second layer of information in which features of each theatre are displayed one by one (period of construction, size, capacity, state of despair, etc.). Visual comparisons across the data set are then possible (middle). Bottom, in this experiment (Dudek, 2005) the selection of a bibliographic item (here a XIXth century photograph) results in the automatic creation of a 3D VRML model containing the architectural content of the source: the graphic can then be queried to get "all other sources related to this architectural content". In other words, the graphic acts not as an end but as a dynamic intermediate between information sets. 


\section{CONCLUSIONS}

Among specialists of historic architecture, computer graphics, and VR in particular, are naturally considered as seducing, but also often needlessly verbose and assertive, and vain in terms of scientific result. We believe this view may change provided that we put methodological issues first. And our claim is that a good way to do so is to integrate concerns stemming from the field of information visualisation in the practice of architectural representation. The past and contemporary examples we have mentioned underline how questions about representation, (understood as an investigative tool, a tool for visualising objects and information) are renewed by the development of computer graphics solutions. Finally, we can conclude with a third claim : the idea that when developping computer graphics technology, application fields should not be limited to validating the technology, but could contribute to question it.

\section{REFERENCES}

Alkhoven, P., The changing image of the city. A study of the transformation of the townscape using Computer assisted Design and visualisation techniques PHD Thesis, University of Utrecht (1993)

Alkhoven, P, 2006. Less is more. Visual truth and the benefits of abstraction in 3D representations of buildings. In Proc. MIA 2006, Mia journal vol0 $n^{\circ} 1$. www.map.archi.fr/mia/journal.

Ando, M., Networked VR for virtual heritage, in HCI International 2003 - vol. 3, LEA publishers.

Barberot, E., 1922. Aide mémoire de l'architecte et du constructeur, Librairie Polytechnique Ch.Béranger.

Bertin, J; [Graphic semiology] Sémiologie graphique, EHESS 1967/1998.

Blaise, J.Y, Dudek I, De Domenico, F, 2006. Spatial distribution and visual analysis of architectural semantic features, Proc. I-KNOW 06, JUCS.

Choisy, A., 1899-1991 [History of architecture] Histoire de l'Architecture Inter-Livres.

De Luca L, Véron, P, Florenzano, M, 2005. "Reverse engineering of architectural buildings based on a hybrid modelling approach", Computers \& Graphics. Vol. 30.

Démians d'Archimbaud, 1987 [Rougiers deserted medieval village] Rougiers village médiéval déserté, Imprimerie Nationale

Dudek I., Blaise, J.Y., 2005. From artefact representation to information visualisation: genesis of informative modelling In LNCS Volume 3638/2005, Proc SmartGraphics 2005.

Dudek I., Blaise, J.Y., 2007. Informative modelling Mia journal vol1S www.map.archi.fr/mia/journal.

Estevez, D,. 2001 [Achitectural drawing and computer graphics] Dessin d'architecture et infographie CNRS Editions, Paris 2001

Fanelli, G., 1980, Brunelleschi, Scala - Becocci, Firenze,

Friendly, M, 1999. Re-visions of Minard in Statistical computing and graphics newsletter vol $11, n^{\circ} 1$.

Kantner, J., 2000. Realism vs Reality: creating virtual reconstructions of prehistoric architecture, in J.A Barcelo, M.Forte, D.H Sanders (Ed.) Virtual reality in archaeology, (Oxford: Archeopress)

Kienreich, W., 2006. Information and Knowledge Visualisation: an oblique view MIA Journal VolO $n^{\circ} .1$.

Lecuyot, G, 2004. With TAISEI/AOROC/ENS La restitution $3 D$ de la ville d'Aï Khanoum in journal CNRS n ${ }^{\circ} 178$

Lenntorp, B, 2003. The drama of real-life in a timegeographic disguise, In Proc. Gèmes Journées Théo Quant.

Lerma, J.L, Vidal, J, Portalés, C, 2004. Three dimensional city model visualisation for real-time guided museum tours The photogrammetric record 19(108).

MHK (Muzeum Historyczne Miasta Krakowa), 2007, (Historical museum of the city of Cracow) Civitas Nostra Cracoviensis, A.D.1650 CD Rom

Müller, U et al., 1997 Damage mapping of historical buildings, in Proc SFIIC 1997

Perkins, A. 2003 The Cone Sisters' Apartments: Creating A Real-Time, Interactive Virtual Tour in Proc. ICHIM 03 Paris France.

Pérouse de Montclos, J.M, 1995, (Ed.) Le guide du Patrimoine - Centre Val de Loire. Hachette.

Spence, R., Information vizualisation. Addison Wesley ACM Press 2001

Suveg, I, Vosselman, G, 2003. Reconstruction of $3 D$ building models form aerial images and maps, ISPRS Journal of Photogrammetry and remote sensing 58

Tajchman J., 1989. Stropy drewniane w polsce. Propozyca systematyki Ośrodek dokumentacji zabytków, Warszawa (1989)

Tufte, E. R. 1997. Visual explanations, Graphic Press, Cheshire, Connecticut

Tufte, E. R. 1990. Envisioning information, Graphic Press, Cheshire, Connecticut

Wittkower, R., 1949-1998. Architectural principles in the age of humanism, Academy editions. 